\title{
Inconsistent screening for lead endangers vulnerable children: policy lessons from South Bend and Saint Joseph County, Indiana, USA
}

\author{
Heidi Beidinger-Burnett ${ }^{1} \cdot$ Lacey Ahern $^{1} \cdot$ Michelle Ngai $^{1} \cdot$ Gabriel Filippelli $^{2}$. \\ Matthew Sisk ${ }^{3}$
}

Published online: 17 December 2018

(C) The Author(s) 2018

\begin{abstract}
Lead exposure is a major health hazard affecting children and their growth and is a concern in many urban areas around the world. One such city in the United States (US), South Bend Indiana, gained attention for its high levels of lead in blood and relatively low testing rates for children. We assessed current lead screening practices in South Bend and the surrounding St. Joseph County (SJC). The 2005-2015 lead screening data included 18,526 unique children. Lead screening rates ranged from 4.7 to $16.7 \%$. More than $75 \%$ of children had 'elevated blood lead levels' (EBLL) $\geq 1$ micrograms per deciliter ( $\mu \mathrm{g} / \mathrm{Dl}$ ) and $9.7 \%$ had an EBLL $\geq 5 \mu \mathrm{g} /$ dL. Over $65 \%$ of the census tracts in SJC had mean EBLL $\geq 5 \mu \mathrm{g} / \mathrm{dL}$, suggesting widespread risk. Inconsistent lead screening rates, coupled with environmental and societal risk factors, put children in SJC at greater risk for harmful lead exposure than children living in states with provisions for universal screening. Indiana and
\end{abstract}

Heidi Beidinger-Burnett

hbeiding@nd.edu

Lacey Ahern

Lhaussam@nd.edu

Michelle Ngai

Michelle.Ngai.2@nd.edu

Gabriel Filippelli

gfilippe@iupui.edu

Matthew Sisk

Lhaussam@nd.edu

1 Eck Institute, Flanner Hall 920, Notre Dame, USA

2 Department of Earth Sciences, Indiana University-Purdue University Indianapolis, 402 North Blackford, Indianapolis, IN 46202, USA

3 Center for Digital Scholarship, University of Notre Dame, 250G Hesburgh Library, Notre Dame, IN 46556, USA 
other states should adhere to the US Centers for Disease Control's guideline and use universal lead testing to protect vulnerable populations.

Keywords Lead poisoning $\cdot$ Testing rate $\cdot$ Universal lead testing

\section{Introduction}

Beginning in the early 1900s, manufacturers incorporated lead into a host of products, mostly lead-based paint and leaded gasoline; global contamination of air, water, and soil resulted [1]. Global production of lead, largely for lead-acid batteries, has increased substantially since the 1970 s, even as lead was largely phased out of paint and gasoline [1]. Lead poisoning is estimated to kill on the order of 500,000 people per year globally, with $82 \%$ of deaths due to lead occurring in low and middle income countries [2].

The primary source of lead exposure in low and middle income countries differs from the United States (US), with the former dominated by battery manufacturing and recycling and the latter by the legacy impacts of lead-based paint and fuel that resulted in concentration of lead in surface soils [3]. Globally, young children living in proximity to areas with high environmental lead contamination are at greatest risk of lead poisoning that can cause detrimental life-long neurological and physiological damage $[4,5]$. Lead can permanently decrease IQ, academic achievement, and economic achievement [6-9]. Further, studies have shown a strong association between childhood lead poisoning and criminal arrests [10,11], as well as other non-cognitive health issues $[12,13]$.

After decades of progress decreasing lead hazards, the US continues to battle the environmental legacy of leaded paint and gasoline. The US Centers for Disease Control (CDC) reports there are at least 4 million households in the US with high levels of environmental lead in which children reside. They further estimate that 500,000 children ages 1-5 have elevated blood lead levels (EBLLs) above 5 micrograms per deciliter $(\mu \mathrm{g} / \mathrm{dL})$, the threshold set by the CDC to initiate case management [6]. US state laws governing lead testing of children vary greatly and are implemented inconsistently, resulting in abysmal testing rates. In the US, only 10 states and the District of Columbia require universal testing and 8 states require targeted testing [14]. Targeted testing refers to the criteria established to identify children who are at-risk of lead poisoning. The remaining 32 states only have screening recommendations and no formal policy [14].

The State of Indiana has no formal policy for blood lead screening levels in children and the overall lead screening rate in Indiana for all children 0-6 years was only $10 \%$ [15]. The US federal government finances a medical services program, called Medicaid, for some low income children. As part of its services, Medicaid requires children enrolled in the program receive lead testing in accordance with CDC guidelines [16]. In 2012, 60\% of all children in Indiana between 0 and 6 years of age were Medicaid-eligible, of whom only $28.7 \%$ were tested [17]. 
A national survey of the number of children tested and the rates of EBLLs in children at the census tract or county level highlighted the failure of the current strategy for identifying and protecting children from the harm of lead exposure [18]. The survey report pointed to a short list of nine "troubled communities" - those with high percentages of children with elevated lead levels-scattered around the US. Although large municipalities appeared on this list, so did several smaller communities with little support for public health surveillance, such as the small post-industrial/university city of South Bend, Indiana. Up to $31 \%$ of children under the age of 7 tested by public and private health providers in South Bend had unsafe levels, the highest in the State of Indiana [18].

We aimed to develop an epidemiologic profile of lead testing. We designed our study to describe and analyze the demographics and spatial distribution of children under 5 years of age (0-4.99 years of age) with elevated lead levels in St. Joseph County (SJC), Indiana. This includes South Bend. We chose under 5 years of age to be more consistent with CDC screening guidelines, in contrast to Reuters [19] who used the state-reported values from 2005 to 2015 for children under 7 years of age. We also examined whether blood lead testing rates and trends adequately captured those children at highest risk for EBLLs.

\section{Methods}

The SJC Health Department maintains a lead database containing the results of every blood lead test conducted, along with associated patient information. The information captured includes, but is not limited to: demographics, pregnancy status, Medicaid status, blood lead level, reason for testing, and physician and laboratory names. For this cross-sectional study, we extracted data between 2005 and 2015 and de-identified individuals to ensure confidentiality and compliance with HIPAA regulations. HIPAA is the Health Insurance Portability and Accountability Act of 1996; US legislation that provides data privacy and security provisions for safeguarding medical information. As part of de-identification, we aggregated at the census tract level the locations of individual residential addresses. We extracted tract boundaries for this, and all other spatial analyses, from US Census Bureau TIGER/ Line dataset [20].

After applying exclusion criteria (explained below), 22,629 lead tests represented 18,526 unique children under 5. Because the data did not allow for appropriate differentiation between confirmatory and routine screening, we included the first lead test for each unique child only. We are aware that this is slightly different from the conventional method using the highest venous or lowest capillary test. We chose this method to draw attention to cases without adequate follow-up. Statistically, the conventional aggregation method changes the mean values slightly, but does not impact the patterns discussed below.

The exclusion criteria included:

(1) duplicate records, 
(2) records noting the same unique identifier, date of birth, and specimen date reporting different blood lead levels,

(3) records with the same unique identifier, but different date of birth,

(4) individuals $\geq 5$ years of age on the date of initial lead test, and

(5) records where the residential address could not be allocated to a specific census tract.

We extracted additional data pertaining to population size, poverty level, and housing age from the American Community Survey (ACS) 5-year estimates at the census tract level in SJC, Indiana.

We performed descriptive analyses for patient demographics and Medicaid status, stratified by blood lead level outcomes. We calculated the annual lead testing rate of children under 5 at between 2009 and 2015 for several census tracts (ACS yearly estimates began in 2009). We generated maps to determine the spatial distribution of EBLLs, in addition to indicators such as median housing age and poverty rates. We evaluated the correlation between socioeconomic risk factors and EBLLs with Spearman's rank correlation coefficient. We conducted all analyses in $\mathrm{R}$ version 3.4.1 and ESRI ArcGIS 10.5.

\section{Results}

Over the 10-year period (2005-2015), health providers performed 22,629 blood lead tests for children under 5 years of age. This led to identification of 18,526 unique individuals (Table 1). Of the 18,526 unique individuals, $75.5 \%(14,000)$ had an EBLL $\geq 1 \mu \mathrm{g} / \mathrm{dL}$.

Both sexes are roughly equally represented in the testing with 49.2 and $50.1 \%$ females and males, respectively (Table 1). The distribution of EBLL among sexes was similar, with a slight increase among males for EBLL 5-9 and $\geq 10 \mu \mathrm{g} / \mathrm{dL}$. The racial composition of the tested individuals consists of $43.3 \%$ white, $19.4 \%$ black, and fewer than $1 \%$ for other subgroups, including Asian/Pacific, American Indian, and multiracial. With respect to ethnicity, a greater proportion of non-Hispanic individuals had been tested, compared to Hispanics. The racial and ethnic composition is based on a person's self-identification with a racial/social group as defined by the US Census Bureau.

EBLLs are linked to Medicaid status (Table 1). Medicaid status is a proxy for low socio-economic status because Medicaid serves children who are from families with low income and fewer assets. For children who receive Medicaid, 93.7\% had an EBLL $1 \mu \mathrm{g} / \mathrm{dL}$ or higher, and for those who were non-Medicaid recipients (usually higher income), $73.9 \%$ had an EBLL $\geq 1 \mu \mathrm{g} / \mathrm{dL}(p<0.0001)$. Additionally, the proportion of Medicaid recipients increases with each incremental rise in blood lead level. For example, while $5.8 \%$ of Medicaid recipients had a BLL of $0 \mu \mathrm{g} / \mathrm{dl}, 26.3 \%$ were between 1 and $4 \mu \mathrm{g} / \mathrm{dL}, 35.2 \%$ were between 5 and $9 \mu \mathrm{g} / \mathrm{dL}$, and $53.7 \%$ were $10 \mu \mathrm{g} / \mathrm{dL}$ or higher. 
Table 1 Demographics of children under 5 years of age stratified by elevated blood lead level (EBLL) in St. Joseph County, IN; analysis conducted 2017-2018

\begin{tabular}{|c|c|c|c|c|c|}
\hline & Total & EBLL $0 \mu \mathrm{g} / \mathrm{dL}$ & $\begin{array}{l}\text { EBLL 1-4 } \mu \mathrm{g} / \\
\mathrm{dL}\end{array}$ & $\begin{array}{l}\text { EBLL 5-9 } \mu \mathrm{g} / \\
\mathrm{dL}\end{array}$ & $\begin{array}{l}\mathrm{EBLL} \geq 10 \mu \mathrm{g} / \\
\mathrm{dL}\end{array}$ \\
\hline $\begin{array}{l}\text { Children under } \\
5\end{array}$ & $100 \%(18,526)$ & $24.4 \%(4526)$ & $65.9 \%(12,201)$ & $8.0 \%(1484)$ & $1.7 \%(315)$ \\
\hline \multicolumn{6}{|l|}{ Sex } \\
\hline Female & $49.2 \%$ (9122) & $50.2 \%(2271)$ & $49.3 \%$ (6014) & $47.0 \%(697)$ & $44.4 \%(140)$ \\
\hline Male & $50.1 \%(9272)$ & $49.3 \%$ (2233) & $50.1 \%(6114)$ & $51.0 \%(757)$ & $53.3 \%(168)$ \\
\hline Unknown & $0.7 \%(132)$ & $0.5 \%(22)$ & $0.6 \%(73)$ & $2.0 \%(30)$ & $2.2 \%(7)$ \\
\hline \multicolumn{6}{|l|}{ Race } \\
\hline $\begin{array}{l}\text { American } \\
\text { Indian }\end{array}$ & $0.1 \%(19)$ & $0.1 \%(4)$ & $0.1 \%(10)$ & $0.3 \%(4)$ & $0.3 \%(1)$ \\
\hline Asian/Pacific & $0.6 \%(120)$ & $1.0 \%$ & $0.6 \%(71)$ & $0.1 \%(2)$ & $0.6 \%(2)$ \\
\hline Black & $19.4 \%(3590)$ & $14.1 \%(640)$ & $20.3 \%(2480)$ & $25.7 \%(382)$ & $27.9 \%(88)$ \\
\hline White & $43.3 \%(8013)$ & $45.4 \%(2053)$ & $43.3 \%(5279)$ & $38.7 \%$ (574) & $34.0 \%$ (107) \\
\hline Multiracial & $0.5 \%(89)$ & $0.4 \%(16)$ & $0.5 \%(65)$ & $0.5 \%(8)$ & $0.0 \%(0)$ \\
\hline Other & $5.9 \%(1088)$ & $10.3 \%(468)$ & $4.7 \%(575)$ & $2.8 \%(42)$ & $1.0 \%(3)$ \\
\hline Unknown & $30.3 \%$ (5607) & $28.7 \%(1300)$ & $30.5 \%(3721)$ & $31.8 \%(472)$ & $36.2 \%(114)$ \\
\hline \multicolumn{6}{|l|}{ Ethnicity } \\
\hline Hispanic & $15.9 \%(2945)$ & $11.8 \%(534)$ & $16.2 \%(1981)$ & $23.8 \%(353)$ & $24.4 \%$ (77) \\
\hline Non-Hispanic & $30.9 \%(5728)$ & $25.4 \%(1150)$ & $32.6 \%(3981)$ & $30.1 \%(447)$ & $47.6 \%(150)$ \\
\hline Unknown & $53.2 \%(9853)$ & $62.8 \%(2842)$ & $51.1 \%(6239)$ & $46.1 \%(684)$ & $27.9 \%(88)$ \\
\hline \multicolumn{6}{|l|}{ Medicaid status } \\
\hline Yes & $22.5 \%(4165)$ & $5.8 \%(265)$ & $26.3 \%$ (3209) & $35.2 \%(523)$ & $53.7 \%(169)$ \\
\hline No & $38.1 \%$ (7054) & $38.4 \%$ (1737) & $38.0 \%$ (4642) & $39.7 \%$ (489) & $27.3 \%(86)$ \\
\hline Unknown & $39.4 \%$ (7307) & $55.8 \%(2525)$ & $35.7 \%(4350)$ & $25.1 \%(372)$ & $19.0 \%(60)$ \\
\hline
\end{tabular}

Due to poor data collection and/or reporting, a significant proportion of the data contained an empty field or was documented as "unknown". For race and ethnicity data, 30.3 and $53.2 \%$ of the children, respectively, were recorded as unknown. Similarly, 39.4\% of the Medicaid status data of the children was recorded as "unknown".

Over the 10-year period, lead testing of children was inconsistent (Fig. 1). In 2011, the number peaked at 2995 children were tested, representing a testing rate of 16.4\%. This peak in testing coincided with a US Housing and Urban Development Grant awarded to the South Bend Housing Authority for lead screening. The trend, however, steadily declined and in 2015 , health care providers tested only 828 children, representing a testing rate of $4.7 \%$.

The rate of children identified with EBLL greater than or equal to $5 \mu \mathrm{g} / \mathrm{dL}$ has significantly decreased from 178.23 per 1000 in 2007 to approximately 60.0 per 1000 during 2010-2015 (Fig. 1). When disaggregated by EBLL, the rate of children with EBLL 5-9 $\mu \mathrm{g} / \mathrm{dL}$ has declined substantially, plateauing from 2010-2015 at approximately 50 per 1000 , while the rate of EBLL $\geq 10 \mu \mathrm{g} / \mathrm{dL}$ has remained relatively constant, averaging 18 per 1000 . 


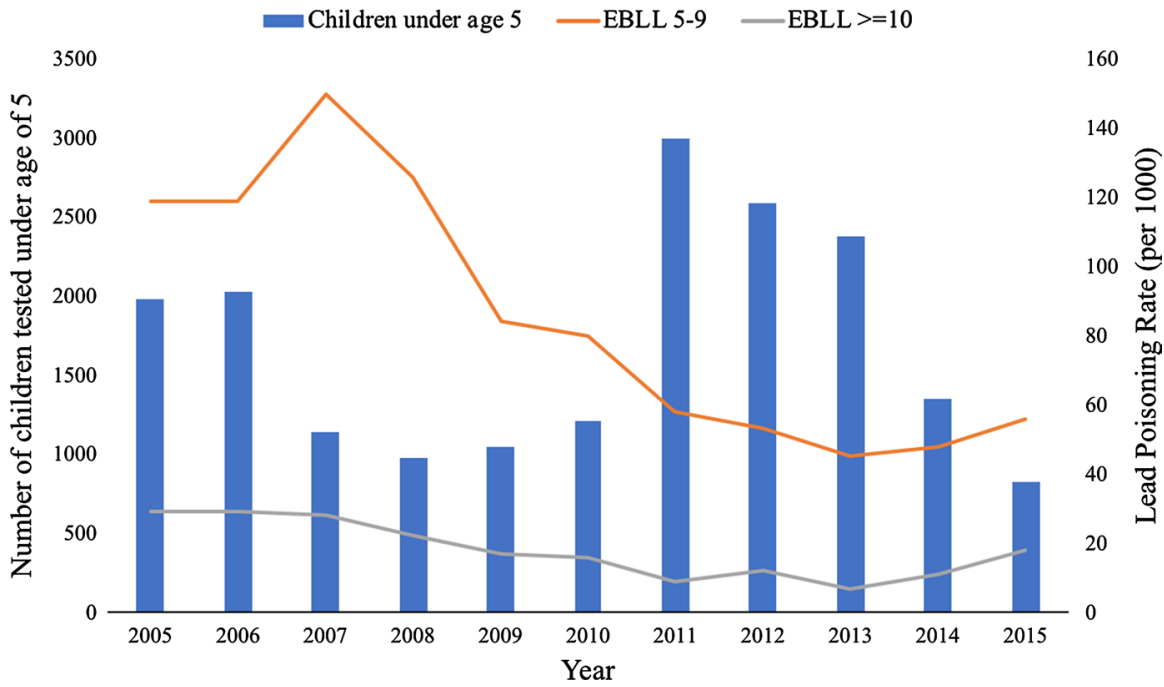

Fig. 1 Lead testing for children under the age of 5 in St. Joseph County, IN. The number of children tested has been inconsistent over the 10-year span, potentially due to gain and loss of monetary incentives to the county health department. The rate of elevated blood level (EBLL) 5-9 $\mu \mathrm{g} / \mathrm{dL}$ steadily declined while rate of EBLL $\geq 10 \mu \mathrm{g} / \mathrm{dL}$ has remained relatively constant. Analysis conducted 20172018

In general, during the period 2005-2015, 9.7\% of children tested had a reported EBLL of $5 \mu \mathrm{g} / \mathrm{dL}$ or greater. Individuals with an EBLL $\geq 5 \mu \mathrm{g} / \mathrm{dL}$ appear to be more centrally located in South Bend within SJC and more densely concentrated within nine census tracts, specifically 4, 5, 6, 7, 19, 21, 22, 27, and 30 (Fig. 2a). Census tracts 6 and 19 had the highest rates of EBLL $\geq 5 \mu \mathrm{g} / \mathrm{dL}$ at 36.4 and $30.0 \%$, respectively. Both tend to contain (1) a higher proportion of households living in poverty and (2) homes constructed before 1940. Both housing age and poverty were associated with an EBLL with a Spearman's correlation of 0.57 and $0.58(p<0.0001)$, respectively. The strength of these relationships is indicative of multiple factors affecting EBLLs rather than attributing the results to a single variable. Disconcertingly, there appear to be low testing rates in these high-risk areas, and more specifically, in census tracts with a higher percentage of impoverished households. In 2015, between 45 and $60 \%$ of individuals in census tract 19 resided in poverty, but only $5.9 \%$ of children under 5 were reported to have been tested for lead levels (Fig. 2b).

We examined this lack of testing further using a 7-year time-series analysis. We observed low and inconsistent testing rates in several census tracts (Table 2). Census tract 19 appears to have the lowest testing rate, with an average of $5.5 \%$ over the 7-year period. Testing in census tract 27 has been inconsistent, with rates ranging between 9.9 and $67.2 \%$. Census tract 6 requires special attention; this area has one of the lowest lead testing rates $(7.3 \%)$ yet contains the highest proportion of children with EBLLs (36.4\%). 
(A)

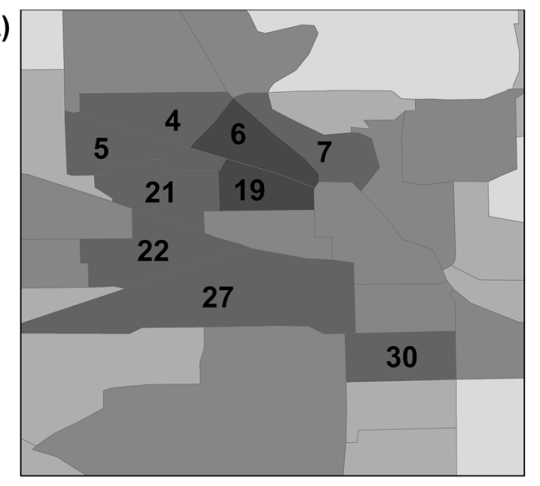

Percentage of children (under 5 )

tested with result $>=5 \mu \mathrm{l} / \mathrm{dl}: 2005-2015$

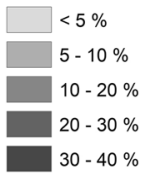

(B)

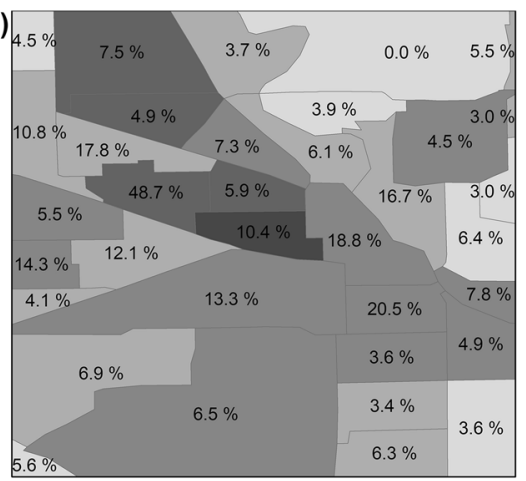

$\mathbf{0 . 0 \%}$ : Percentage of children under 5 tested in 2015 Percentage of individuals in poverty in 2015

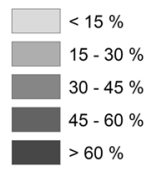

Fig. 2 Spatial map of a central location in St. Joseph County. a Depicts a cluster of census tracts that have a relatively high percentage of children with an EBLL $\geq 5 \mu \mathrm{g} / \mathrm{dL}$ for $2005-2015$. Census tracts 6 and 19 (shown in red) are considered "hot spots", with over $30 \%$ of tested children having an EBLL $\geq 5 \mu \mathrm{g} / \mathrm{dL}$. b The color represents percentage of individuals living in poverty within that census tract; the color deepens with increasing percentage. The superimposed numbers dictate the corresponding lead testing rate within that census tract for 2015. Analysis conducted 2017-2018

Table 2 Lead testing rates between 2009 and 2015 in children under 5 years of age in St. Joseph County, IN

\begin{tabular}{lrrrrrrr}
\hline \multirow{2}{*}{ Census tracts } & \multicolumn{7}{l}{ Years } \\
\cline { 2 - 8 } & 2009 & 2010 & 2011 & 2012 & 2013 & 2014 & 2015 \\
\hline 4 & 6.9 & 8.0 & 22.1 & 15.8 & 16.3 & 7.6 & 4.9 \\
5 & 11.9 & 21.1 & 35.4 & 27.3 & 24.5 & 17.2 & 20.8 \\
6 & 5.6 & 13.9 & 43.2 & 44.1 & 18.5 & 16.4 & 7.3 \\
7 & 2.2 & 8.1 & 22.9 & 24.4 & 21.0 & 13.0 & 6.1 \\
19 & 3.2 & 4.0 & 4.3 & 5.2 & 7.7 & 8.5 & 5.9 \\
21 & 16.4 & 23.6 & 29.7 & 37.3 & 38.0 & 20.0 & 48.7 \\
22 & 16.3 & 21.9 & 38.2 & 27.6 & 33.5 & 17.1 & 13.3 \\
27 & 9.9 & 18.0 & 67.2 & 42.5 & 39.1 & 11.8 & 13.3 \\
30 & 7.2 & 9.3 & 16.4 & 16.8 & 11.8 & 21.9 & 3.6 \\
\hline
\end{tabular}

Analysis conducted 2017-2018

\section{Discussion}

Blood lead testing rates varied substantially among census tracts and over time in SJC, and without any evident strategy to protect children at greatest risk of EBLL. On average, only $10 \%$ of children under 5 had been tested for lead during 
2005-2015 and no census tract reached close to the $100 \%$ recommended by the US CDC. Of the 75 census tracts in SJC, 49 (65\%) had an EBLL greater than or equal to $5 \mu \mathrm{g} / \mathrm{dL}$, suggesting that risk exists beyond the center city of South Bend. Such low and inconsistent testing make it difficult to draw any conclusion about the scope of the EBLL problem among children in SJC. This, in turn, makes it difficult for public health officials to allocate resources properly and protect children from lead poisoning.

This study shows the importance of describing the environmental and societal risk factors associated with EBLL. Housing age and poverty are correlated with an EBLL, placing children at greater risk of lead poisoning. Homes constructed prior to 1950 were painted with lead-based paint, exposing children to chips of paint and leaded dust. Poverty is likely correlated with the state of disrepair of older homes and the inability to remediate lead hazards. The spatial analysis shows that older homes and poverty are concentrated in the inner city of South Bend, exemplifying the negative impact a child's address can have on his or her health. Spatial analysis can aid in the identification of high-risk populations, promoting a more cost-effective method for resource allocation and targeted testing.

\section{Public health implications}

Even after decades of research and legislation to remove lead from paint and gas, globally the incidence of lead poisoning remains high in urban areas. Children of color in low income households who inhabit the polluted centers of our older cities without the benefits of adequate nutrition, education, and health care remain at particular risk [21]. To create lead-safe environments and to provide environmental justice for urban dwellers, newer approaches are needed to assess current lead exposure mechanisms and to understand fully the health implications of chronic lead exposure.

There are significant economic and societal costs associated with lead poisoning - and with lack of action to test children, remediate housing, and treat those poisoned. At the time the poisoned child enters school, he or she may not be capable of performing well without extra educational support ('special education services' required by law in the US), resulting in increased costs and resources. A child who drops out of secondary school is likely to see a significant decrease in lifetime earnings, and that decreases tax revenues and increases social service costs.

Prevention of lead poisoning is cost-effective and necessary to avoid the life-long effects and costs. Based upon 2015 data, there were 17,617 children under 5 living in SJC. A cost-benefit analysis was conducted to quantify the economic benefit of lead exposure prevention and the investment needed to conduct lead screening [22]. Given that the cost of a blood lead test ranges from $\$ 10$ to $\$ 75$, the cost of screening 17,617 children in SJC would cost between $\$ 176,170$ and $\$ 1,321,275$ [22]. This initial investment of \$10-\$75 would be paid for by public (Medicaid) and private health insurance. Our cost-benefit analysis estimates that an investment of \$10-\$75 in lead screening would yield a return of \$17-\$221 in decreased health care costs, lifetime earnings, and direct costs of criminal activity [22, 23]. Thus, SJC could 
expect a return of $\$ 2,900,489-\$ 99,399,375$. Those returns would be distributed across various entities. The health care system (public and private) would achieve cost savings because early detection of a lead poisoned child would lower life-time health care costs. Schools would serve fewer children with developmental disabilities resulting in a cost savings. Ultimately, children would experience the greatest benefit, resulting in greater student achievement and increased lifetime earnings.

This study has demonstrated a lack of coherent laws governing lead testing and case management that has led to haphazard and inequitable strategies in Indiana. The result is that children are at undue risk for developing long-term problems. While Indiana does not have formal policy governing lead testing, states such as Maryland, Iowa, and Vermont benefit from laws on universal lead testing for children and have achieved significant decreases in lead poisoning rates [14]. Since 1994, Maryland has accomplished a $98 \%$ decrease in childhood lead poisoning, as a result of the implementation and enforcement of Maryland's 1994 Reduction of Lead Risk in Housing Act [24]. In Indiana, 'case management' remains inconsistent, with state law requiring case management for EBLLs $\geq 10 \mu \mathrm{g} / \mathrm{dL}$ and the Indiana State Department of Health recommending the initiation of case management for EBLLs $\geq 5 \mu \mathrm{g} / \mathrm{dL}$ [15]. Case management includes a nutritional and developmental milestones assessment, an environmental assessment to identify the sources of lead exposure, and follow-up testing to monitor lead levels [25]. We recommend a statewide policy in Indiana that adopts the US CDC's guideline to require universal lead testing and implement case management at $5 \mu \mathrm{g} / \mathrm{dL}$ or higher.

The World Health Organization (WHO) also recognizes that there is a lack of guidelines and regulations for lead prevention and management globally. Currently, the WHO is developing a set of guidelines to provide evidence-based strategies for policy makers and health providers [26].

Recognition of the adverse effects from lead exposure has received international attention and, as early as 1989, prompted its inclusion in conventions, such as the Convention on the Rights of the Child. While many countries have actively engaged in efforts against lead poisoning, especially through the enforcement of bans on leaded gasoline and paint, other countries have yet to adopt these measures. A significant reduction in blood lead levels in children is a direct result of these restrictions. Vigilance in recognizing, reducing, and possibly eliminating other key sources of lead, such as lead-acid batteries, is essential in the continued efforts moving forward. To address lead as a global health issue, concurrent action will be needed: surveillance and testing, enacting policy to reduce lead poisoning, coupled with strong and consistent implementation.

Mindful of WHO's objectives and with success seen in other US states, there is no safe level of lead; policy makers must act to protect our children and prevent lead poisoning.

Open Access This article is distributed under the terms of the Creative Commons Attribution 4.0 International License (http://creativecommons.org/licenses/by/4.0/), which permits unrestricted use, distribution, and reproduction in any medium, provided you give appropriate credit to the original author(s) and the source, provide a link to the Creative Commons license, and indicate if changes were made. 


\section{References}

1. Landrigan PJ, and 46 others. The Lancet Commission on Pollution and Health. Lancet. 2018;391:407-8.

2. GBD 2015. Risk Factors Collaborators. Global, regional, and national comparative risk assessment of 79 behavioural, environmental and occupational, and metabolic risks or clusters 64 of risks, 1990-2015: a systematic analysis for the Global Burden of Disease. Lancet. 2016;388:1659-724.

3. Filippelli GM, Taylor MP. Addressing pollution-related global environmental health burdens. GeoHealth. 2018;2(1):2-5.

4. Bellinger D. Very low lead exposures and children's neurodevelopment. Curr Opin Pediatr. 2008;2:172-7.

5. Clune ALFH, Riederer AM. Mapping global environmental lead poisoning in children. J Health Pollut. 2011;1:16-25.

6. Lead. Center for Disease Control; 2018. cdc.gov. https://www.cdc.gov/nceh/lead/. Accessed 10 May 2018.

7. Bellinger D. Childhood lead exposure and adult outcomes. JAMA. 2017;12:1219-20.

8. Binns HJ, Campbell C, Brown MJ. Interpreting and managing blood lead levels of less than $10 \mu \mathrm{g} /$ $\mathrm{dL}$ in children and reducing childhood exposure to lead: recommendations of the Centers for Disease Control and Prevention Advisory Committee on Childhood Lead Poisoning Prevention. J Pediatr. 2007;5:e1285-98.

9. Tarrago O, Brown MJ, ATSDR. Case studies in environmental medicine: lead toxicity. Center for Disease Control; 2017. https://www.atsdr.cdc.gov/csem/lead/docs/CSEM-Lead_toxicity_508.pdf. Accessed 3 Sep 2017.

10. Mielke $\mathrm{H}$, Zahran $\mathrm{S}$. The urban rise and fall of air lead $(\mathrm{Pb})$ and the latent surge and retreat of societal violence. Environ Int. 2012;43:48-55.

11. Needleman H, McFarland C, Fienberg S, Tobin M. Bone lead levels in adjudicated delinquents: a case control study. Neurotoxicol Teratol. 2002;6:711-7.

12. Obeng-Gyasi E, Armijos R, Weigel A, Filippelli G, Sayegh M. Cardiovascular-related outcomes in U.S. adults exposed to lead. Int J Environ Res Public Health. 2018;4:759-75.

13. Obeng-Gyasi E, Armijos R, Weigel A, Filippelli G, Sayegh M. Hepatobiliary-related outcomes in US adults exposed to lead. Environments. 2018;4:46-63.

14. Dickman J. Children at risk: gaps in state lead screening policies. Safer Chemicals, Healthy Families; 2017. https://saferchemicals.org/children-at-risk/. Accessed 1 Sep 2017.

15. Childhood lead surveillance report: environmental public health led and healthy homes program. Indiana State Department of Health; 2017. https://www.in.gov/isdh/files/lead\%20report\%20201 6-new.pdf. Accessed 10 Sep 2017.

16. Coverage of blood lead testing for children enrolled in Medicaid and the children's health insurance program. Centers for Medicaid and Medicare Services; 2016. https://www.medicaid.gov/feder al-policy-guidance/downloads/cib113016.pdf Accessed 15 Jan 2017.

17. Lead screening requirements and medical management recommendations: for children ages 6 to 84 months. Indiana State Department of Health; 2013. https:/www.in.gov/isdh/files/Case_Manag ement_Chart_Rev_H_-_2013.pdf. Accessed 10 Sep 2017.

18. Pell M, Schneyer J. Unsafe at Any Level: the thousand of U.S. locales with lead poisoning is worse than in Flint. Reuters Investigates; 2016. http://www.reuters.com/investigates/special-report/usalead-testing/. Accessed 10 Sep 2017.

19. Filippelli GM, Laidlaw MAS. The Elephant in the Playground: confronting lead-contaminated soils as an important source of lead burdens to urban populations. Perspect Biol Med. 2010;53:31-45.

20. Geography. US Census Bureau; 2017. https://www.census.gov/geo/maps-data/data/tiger-line.html. Accessed Dec 2017.

21. Kemper AR, Bordley WC, Downs SM. Cost-effectiveness analysis of lead poisoning screening strategies following the 1997 guidelines of the Centers for Disease Control and Prevention. Arch Pediatr Adolesc Med. 1998;152:1202-8.

22. Gould E. Childhood lead poisoning: conservative estimates of the social and economic benefits of lead hazard control. Environ Health Perspect. 2009;7:1162-7.

23. McKinney J. Lead poisoning in Maryland drops to lowest recorded levels, testing increases in first year of state initiative. Maryland Government: Department of the Environment; 2017. http://news. 
maryland.gov/mde/2017/10/25/lead-poisoning-in-maryland-drops-to-lowest-recorded-levels-testi ng-increases-in-first-year-of-state-initiative/. Accessed 10 May 2018.

24. WHO. Lead poisoning and health. World Health Organization; 2018. http://www.who.int/newsroom/fact-sheets/detail/lead-poisoning-and-health. Accessed 7 Sep 2018.

25. Centers for Disease Control. Recommended actions based on blood lead level. 2018. https://www. cdc.gov/nceh/lead/acclpp/actions_blls.html. Accessed 7 Nov 2018.

26. WHO. Lead Poisoning Prevention Week: ban lead paint. World Health Organization; 2016. http:// www.euro.who.int/en/health-topics/environment-and-health/pages/news/news/2016/10/lead-poiso ning-prevention-week-ban-lead-paint. Accessed 7 Sep 2018.

Heidi Beidinger-Burnett Ph.D. is Assistant Professional Specialist (Faculty) in the Eck Institute for Global redesign, curriculum evaluation, and development. I have spent my career focused on public health and public education. Currently, I am engaged in community-based participatory research focused on lead prevention, HIV and infant mortality. My current projects are focused on the development of a low-cost, scalable home lead test kit and the barriers and facilitators of mental health care for persons living with HIV. In addition to my research, I teach scientific writing, qualitative research methods and leadership. Prior to my appointment at Notre Dame, I worked as a Consultant in K-12 Education for nearly 10 years. I developed expertise in leadership, school redesign, curriculum evaluation, and development.

Lacey Ahern BS, MPH, is Program Director at Global Partners in Care, Notre Dame, Indiana, an organization that works to enhance access to palliative care globally and an Adjunct Assistant Professor in the Eck Institute for Global Health at the University of Notre Dame, Notre Dame, Indiana, USA. She works on community-based health interventions, palliative care access, use of mhealth technologies, and maternal and child health services-particularly looking at quality of care and infant mortality and perinatal surveillance. She has spent the past 15 years engaged in international health and development work, including time living and working in East Africa with the United Nations Population Fund, the Congregation of Holy Cross, Uganda Martyrs University, the Palliative Care Association of Uganda, and other local organizations. She holds a Master of Public Health Degree in Global Health from the Rollins School of Public Health at Emory University.

Michelle Ngai works with students in the Master of Science in Global Health Program at the Eck Institute for Global Health at the University of Notre Dame. In this role, she is training students to join the global health sector by instructing them to critically evaluate issues impacting the health of the world's population, and promoting cross-disciplinary and cross-cultural dialogue. Originally from Canada, Michelle is a Graduate of McGill University, with a Bachelor of Science Degree in Physiology and International Development. She also completed a Master of Public Health Degree at Imperial College London, followed by a Ph.D. at the University of Notre Dame.

Gabriel Filippelli BS, Ph.D. is Professor, Department of Earth Sciences, Indiana University Purdue University, Indiana, USA. I have worked extensively on the chemistry and geologic history of nutrient cycling in the ocean and on land. Current research projects involve determining the controls on nutrient cycling on land during glaciation, examining the timing and driving forces of biological productivity in the ocean, assessing the content and distribution of the potentially harmful element mercury in coal resources of Indiana and examining the links between lead distribution and children's blood lead levels in urban areas.

Matthew Sisk is a Spatial Data Specialist and Geographic Information Systems Librarian based in Notre Dame's Navari Family Center for Digital Scholarship. His research focuses on human-environment interactions, the spatial scale environmental toxins and community-based research. He received his BS from the University of South Carolina in Marine Science and Anthropology and his MA and Ph.D. in Archaeology from Stony Brook University. 